\title{
Application of Ipomoea batatas starch as suspending agent in acetaminophen suspension
}

\author{
Onyishi Ikechukwu V. *, Chime Salome A. and Kanu Ifeoma
}

Department of Pharmaceutical Technology and Industrial Pharmacy, University of Nigeria, Nsukka 410001, Nigeria.

Accepted 16 December, 2013

\begin{abstract}
Natural plant mucilage has gained importance over synthetic ones because of low toxicity, low cost and good availability. The objective of the study was to search for a cheap and effective natural raw material that can serve as an alternative suspending agent in the formulation of acetaminophen suspension. The phytochemical and the physicochemical properties of the mucilage of Ipomoea batatas L. were studied. The suspending properties of mucilage extract of $I$. batatas $L$. were evaluated comparatively with that of acacia and sodium alginate using model formulations at concentrations of $5,10,15$ and $20 \% \mathrm{w} / \mathrm{v}$. The suspensions were evaluated for rheological properties, sedimentation profile and stability studies. The results showed the presence of flavonoids, saponin, protein, carbohydrate and reducing sugars. The rheological properties of suspension showed that increase in concentration increased the viscosity of suspension, while increase in temperature did not significantly increased the viscosity of suspension ( $p$ $<0.05)$. The order of stability of suspension in terms of sedimentation profile ranked thus: $E(20 \% \mathrm{w} / \mathrm{v}$ potato starch $)>D(15 \% \mathrm{w} / \mathrm{v}$ potato starch $)>F(10 \% \mathrm{w} / \mathrm{v}$ sodium alginate $)>C(10 \% \mathrm{w} / \mathrm{v}$ potato starch $)>$ B $(5 \% \mathrm{w} / \mathrm{v}$ potato starch). These results indicate that mucilage from $I$. batatas $\mathrm{L}$. in acetaminophen suspension has low sedimentation rate, medium viscosity and easily dispersible and can therefore serve as suspending agent in formulations of suspensions of sparingly soluble drugs.
\end{abstract}

Key words: Suspensions, potato starch powder, acetaminophen, rheological properties, physicochemical properties.

\section{INTRODUCTION}

Pharmaceutical suspensions are liquid dosage forms that require the addition of suspending agents in order to stabilize their system (Mahmud et al., 2010). These suspending agent increase sedimentation volume, ease redispersibility, enhance pourability and prevent compact cake formation. Suspending agents are grouped into three classes: synthetic, semi synthetic and the natural polysaccharides, in which class acacia, tragacanth and starch belong to the latter class (Mbang et al., 2004; Mahmud et al., 2010). The challenge of suspension formulation concerns sedimentation, caking and resuspension (Ogaji and Hoag, 2011). A suspension should not settle rapidly, it should be sufficiently fluid to flow easily under the condition of administration. As a suspension is energetically unstable, the particles that have settled tend to interact to form a cake or hard crystalline network. It is required that suspensions are formulated such that caking is minimized and so that the particles that have settled may be readily redispersed upon shaking (Ogaji and Hoag, 2011). In a pharmaceutical suspension, a suspending agent helps the drug stay suspended thereby reducing caking at the bottom of the preparation. Consistency of the solute throughout the suspending medium is facilitated with the drug or solute staying suspended in the continuous phase (Ogaji and Hoag, 2011). In recent years, 
pharmaceutical scientists have been paying increasing attention to the extraction, development and use of starches in the formulation of dosage forms (Garr and Bangudu, 1991; Alebiowu and Itiola, 2003). Natural polymers have advantages over the synthetic and semisynthetic polymers which include better biocompatibility, relatively cheap, easily accessible, physiologically inert and do not exert pharmacological effect. Therefore, the danger of use of synthetic polymer matrix materials which often goes along with detrimental effects on incorporated drug during manufacturing of formulations or after application are completely avoided (Reithmeier et al., 2001). Potato starch is a tropical tuber that store edible material in subterranean roots or tubers (Oke, 1967). It mainly consists of starch, which is the only qualitatively important digestible polysaccharides being regarded a nutritionally superior to low molecular carbohydrate or sugars (Malcolm, 1990). The objectives of the study are to formulate acetaminophen suspension using starch from sweet potatoes as the suspending agent and to compare the suspending properties of potato starch with that of acacia and sodium alginate in acetaminophen suspension.

\section{MATERIALS AND METHODS}

Acetaminophen (May and Baker, England), acacia, sodium alginate (BDH Chemicals Ltd., England), saccharin sodium (Sigma-Aldrich, Germany), distilled water (Lion water, Nsukka, Nigeria). Ipomoea batatas starch was obtained from a batch processed in our laboratory. All other reagents and solvents were analytical grade and were used as supplied.

\section{Extraction and purification of potato starch}

I. batatas $L$. were purchased from the market of Nsukka, Nigeria in early December, 2011. The potatoes were cleaned by removing the soil and stones and washed with water. The bark were properly peeled and rewashed with clean water containing $1 \%$ sodium metabisulphite (an anti-oxidant). After washing, the potatoes were reduced to a fine pulp in a rasping machine of hammer mill type. The pulp was separated from the rasped potato by means of a muslin cloth and agitation was provided using hands. During screening, the water used contained $1 \%$ sodium metabisulphite in order to avoid discolouration of the starch by oxidative enzymes. The obtained starch suspension was allowed to settle under gravity and the supernatant was decanted. The starch suspension was washed severally using three times its volume of water for 3 days with intermittent shaking and changing of water. Dewatering was done using a bag with pores of about $100 \mathrm{~mm}$ and pressure was applied using hand. The drying of the starch was carried out under the sun (Ajali, 2004).

\section{Phytochemical screening}

Phytochemical tests were carried out on the potato starch for the presence of tannins, saponins, flavonoids, resins, fats and oils, glycosides, proteins, carbohydrates and reducing sugars. The tests were carried out using standard procedures of analysis (Harborne, 1993; Sofowora, 1993; Trease and Evans, 2002).

\section{PHYSICOCHEMICAL ANALYSIS OF POTATO STARCH}

\section{Micromeritic properties of potato starch}

\section{Bulk and tapped densities}

A $50 \mathrm{~g}$ quantity of starch powder was weighed out and placed in a $100 \mathrm{ml}$ graduated cylinder. The volume occupied by the sample was noted as the bulk volume. The bulk density was obtained by dividing the mass of the sample by the bulk volume, as shown in Equation 1 (Aulton, 2007; Ngwuluka et al., 2010):

Bulk density $=\frac{\text { Mass of Powder }(\mathrm{M})}{\text { Bulk volume of powder }\left(\mathrm{V}_{\mathrm{B}}\right)}$

The cylinder was tapped on a wooden platform by dropping the cylinder from a height of one inch at $2 \mathrm{~s}$ interval until there was no significant change in volume reduction. The volume occupied by the sample was then recorded as the tapped volume. The tapped density was calculated using the formula:

Tapped density $=\frac{\text { Mass of sample }(\mathrm{M})}{\text { Tapped volume }\left(\mathrm{V}_{\mathrm{T}}\right)}$

\section{Flow rate and angle of repose}

A funnel was properly clamped onto retort stand. The funnel orifice diameter, base diameter and efflux tube length were appropriately measured. A $50 \mathrm{~g}$ quantity of the sample was weighed out and gradually placed into the funnel with the funnel orifice closed with a shutter. The time taken for the entire sample in the funnel to flow through the orifice was noted. The flow rate was gotten by dividing the mass of the sample by the time of flow in seconds. The static angle of repose was determined using the fixed base cone method (Aulton, 2007; Ngwuluka et al., 2010). About $50 \mathrm{~g}$ of the sample was transferred into an open-ended cylinder placed on a static base cone on a horizontal surface. The cylinder was gradually withdrawn vertically and the sample formed a cone-shaped heap. The height of the sample was determined using a cathetometer; the radius was gotten by dividing the fixed diameter by two. Angle of repose $(\theta)$ for each sample was obtained using the equation:

$\theta=\frac{\tan ^{-1} \text { height }}{\text { radius }}$

Also, the moisture content and ash content were determined.

\section{Proximate analysis}

Moisture and ash contents of the I. batata starch samples were determined by standard methods of analysis (AOAC, 1990).

\section{Solubility}

The solubility of potato starch powder was tested in water (cold and hot), methanol, ethanol and chloroform.

\section{Rheological analysis}

Potato starch powder mucilage $(2 \% \mathrm{w} / \mathrm{v})$ was prepared in distilled 
water and the viscosities in $\mathrm{cp}$ were determined using a viscometer (Universal torsion viscometer, Gallenkamp, England) (Onyechi, 2008).

\section{Effects of concentration on viscosity}

Potatoes starch mucilage containing $0.5,1,2,3,4$ and $5 \% \mathrm{w} / \mathrm{v}$ of starch were prepared in distilled water and the viscosities were recorded at room temperature $\left(28^{\circ} \mathrm{C}\right)$.

\section{Effects of temperature on viscosity}

Also, about $2 \% \mathrm{w} / \mathrm{v}$ of potatoes starch powder were prepared and the viscosities were determined at $28,40,60,80$ and $100^{\circ} \mathrm{C}$, respectively.

\section{Effects of pH and electrolytes on the viscosity}

A $0.1 \mathrm{M}$ of $\mathrm{HCl}$ and $\mathrm{NaCl}$, respectively were added to $2 \% \mathrm{w} / \mathrm{v}$ of starch mucilage and the viscosities were determined. A small amount of conc. $\mathrm{HCl}$ and $\mathrm{NaOH}$ were added to different portions of starch mucilage to modify the $\mathrm{pH}$, and the $\mathrm{pH}$ was recorded. The viscosities of the different mucilages were recorded.

\section{Formulation of acetaminophen suspension}

Acetaminophen suspensions containing $2.4 \% \mathrm{w} / \mathrm{v}$ of acetaminophen were prepared using acacia $(10 \% \mathrm{w} / \mathrm{v})$, sodium alginate $(10 \%$ $\mathrm{w} / \mathrm{v})$ or potatoes starch $(0,5,10,15$ and $20 \% \mathrm{w} / \mathrm{v})$ as the suspending agent as shown in Table 1. Mucilages of the suspending agent were prepared by hydration using part of the vehicle. The solid components of the formulation were finely triturated with the aid of mortar and pestle. The suspending agent was added to the powdered drug and triturated until homogeneous slurry was obtained. Sodium benzoate $(0.02 \%)$ was used as the preservative and saccharine (1\%) was used as the sweetener. This was transferred into a $100 \mathrm{ml}$ beaker and the remaining vehicle was used to rinse the mortar to make up the required volume.

\section{Evaluation of acetaminophen suspension}

\section{Sedimentation volume}

The sedimentation volume of the suspensions was determined by measuring the volume of the sediments in the suspension placed in the measuring cylinders. The sedimentation volume was recorded at $30 \mathrm{~min}$ interval for $6 \mathrm{~h}$, then at 12, 24 and $48 \mathrm{~h}$. The sedimentation volume $(F)$ was calculated using the formula:

$F=\frac{V_{u}}{V_{0}}$

Where $\mathrm{V}_{\mathrm{u}}=$ height of sediment at a given time and $\mathrm{V}_{\mathrm{o}}=$ original volume of sediment before settling occurred (Mahmud et al., 2010).

\section{Rheological measurements}

The viscosity of each batch of the suspension was determined using a viscometer (Universal torsion viscometer, Gallenkamp, England).

\section{pH stability studies}

The $\mathrm{pH}$ of the suspensions were determined using $\mathrm{pH}$ meter $(\mathrm{pH}$ $\mathrm{ep}^{\circledR}$ Hanna instrument, Padova, Italy) in time dependent manner (1 day, 30 and 60 days).

\section{Statistical analysis}

Statistical analysis was done using statistical package for social sciences (SPSS) version 14.0 (SPSS Inc. Chicago, IL.USA). All values were expressed as mean \pm standard deviation (SD). Data were analysed by one-way analysis of variance (ANOVA). Differences between means were assessed by a two-tailed student's T-test. $P<0.05$ was considered statistically significant.

\section{RESULTS AND DISCUSSION}

\section{Phytochemical properties}

The result of phytochemical analysis of potato starch presented in Table 2 showed that the starch contains flavonoids, glycosides, saponin, protein, carbohydrate, reducing sugars, and fats and oils. The presence of these constituents showed some benefits of natural products since not only will they act as a suspending agent but will provide some nutritional and pharmacological activity. Phytochemicals are non-nutritive plant chemicals that have protective or disease preventive properties. Plants produce these chemicals substances to protect themselves, and they are also believed to protect humans against certain diseases (Edeoga et al., 2005).

\section{Physicochemical properties}

\section{Solubility properties of potato starch}

Potato starch was found to be insoluble in cold water, ethanol, methanol, acetone and chloroform, but it was soluble in hot water. Therefore, potato starch exhibited properties as a good suspending agent.

\section{Micromeritic properties}

The results of the micromeritic properties of potato starch presented in Table 3 indicate that the starch exhibited poor flowability values. However, flow rate and angle of repose obtained were within the acceptable limits for powder fluidity. Angle of repose was used as an indirect method of assessing flowability of powder because of their relationship with interparticle cohesion. The starch had angle of repose of $30^{\circ}$ which showed that the starch had high interparticulate friction and hence exhibited poor flow. Hausner's ratio $\leq 1.25$ indicates good flow, while $>$ 1.25 indicates poor flow (Yüksel et al., 2007; Chime et al., 2012). Also, Carr's index in the range of 5 to 16 indicates good flow, 18 to 21 shows fair flow, while values above 
Table 1. Composition of acetaminophen suspension.

\begin{tabular}{ccccccc}
\hline Batch & $\begin{array}{c}\text { Acetaminophen } \\
(\%)\end{array}$ & $\begin{array}{c}\text { Acacia } \\
(\%)\end{array}$ & $\begin{array}{c}\text { Sodium alginate } \\
(\%)\end{array}$ & $\begin{array}{c}\text { Potatoes starch } \\
(\%)\end{array}$ & $\begin{array}{c}\text { Sodium benzoate } \\
(\%)\end{array}$ & $\begin{array}{c}\text { Saccharine } \\
(\%)\end{array}$ \\
\hline A & 2.4 & 10 & 0 & 0 & 0.02 & 1.0 \\
B & 2.4 & 0 & 0 & 5 & 0.02 & 1.0 \\
C & 2.4 & 0 & 0 & 10 & 0.02 & 1.0 \\
D & 2.4 & 0 & 0 & 15 & 0.02 & 1.0 \\
E & 2.4 & 0 & 0 & 20 & 0.02 & 1.0 \\
F & 2.4 & 0 & 10 & 0 & 0.02 & 1.0 \\
\hline
\end{tabular}

A-F represents various formulations of acetaminophen suspension.

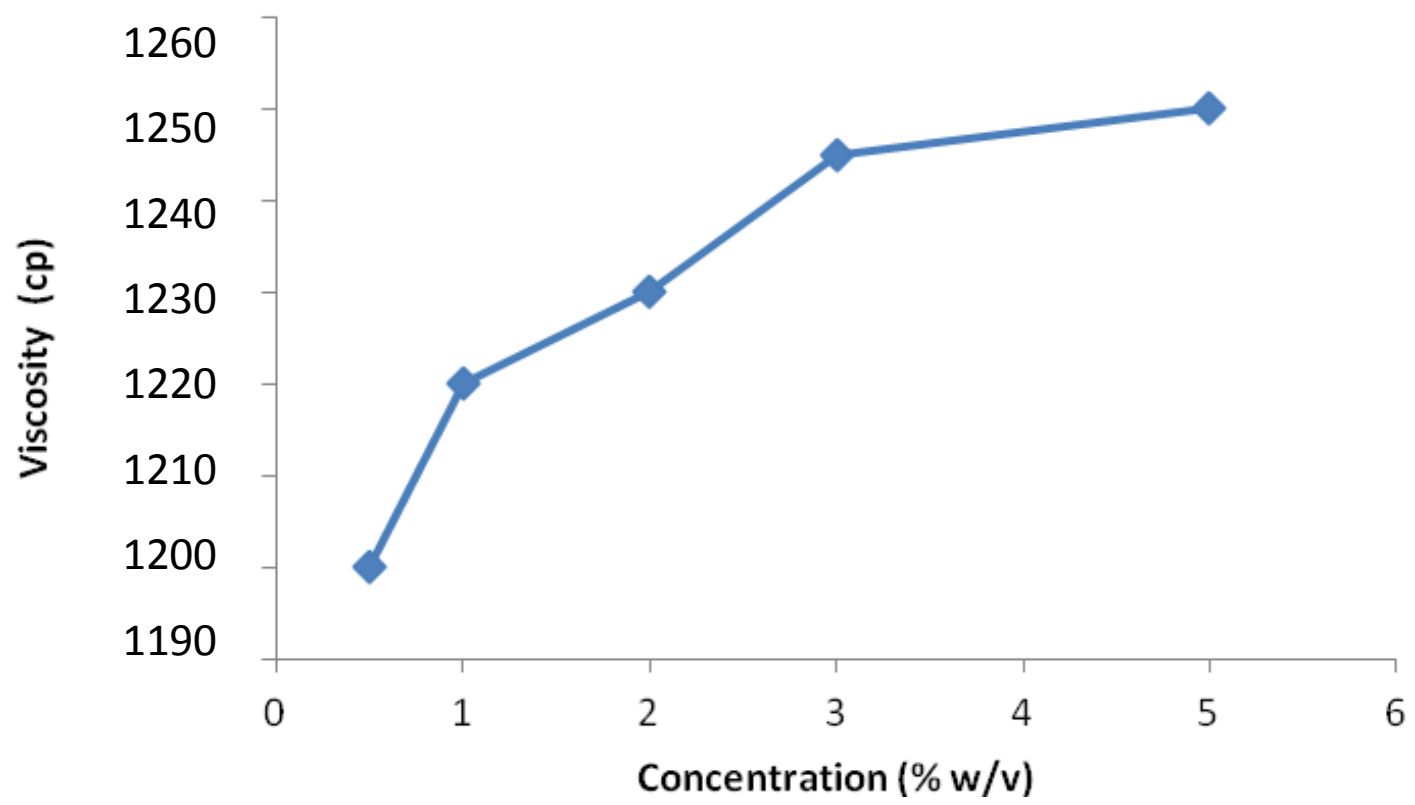

Figure 1. Effect of concentration on the viscosity of potato starch dispersion.

Table 2. Phytochemical content of Ipomoea batatas starch.

\begin{tabular}{lc}
\hline Chemical component & Results \\
\hline Flavonoids & + \\
Saponin & + \\
Carbohydrates & + \\
Reducing sugars & + \\
Tannins & + \\
Resins & + \\
Glycosides & + \\
Proteins & + \\
Fats and oil & + \\
\hline
\end{tabular}

+ Present

38 shows very poor flow (Yüksel et al., 2007; Chime et al., 2012). The results of Hausner's quotient also shown in Table 3 showed that potato starch had values significantly lower than 1.25 and therefore had poor flow ability due to high interparticulate friction in the bulk powder. The results of Carr's compressibility index also shown in Table 3 showed that potato starch had values of approximately $38^{\circ}$ and hence exhibited poor flow.

\section{Rheological properties of starch}

The rheological properties of potato starch dispersions in distilled water showed that the viscosity of starch dispersions had a close to linear relationship at concentrations 0.5 to $5 \% \mathrm{w} / \mathrm{v}$ of potato starch. The viscosity increased continually up to a concentration of 5 $\% \mathrm{w} / \mathrm{v}$ as shown in Figure 1. Potato starch powder on initial increase in temperature absorbed more water showing a high initial peak viscosity. The results indicated that the gelatinization temperature of potato starch 
Table 3. Physicochemical properties of potato starch powder.

\begin{tabular}{lcccccccc}
\hline Sample & $\mathbf{B D}(\mathbf{g} / \mathbf{m l})$ & $\mathbf{T D}(\mathbf{g} / \mathbf{m l})$ & Flow rate $(\mathbf{g} / \mathbf{s})$ & $\mathbf{A . R}\left(^{\circ}\right)$ & HQ & $\mathbf{C l}(\%)$ & $\mathbf{M C}(\%)$ & AC $(\%)$ \\
\hline Potato starch & $0.60 \pm 0.10$ & $0.96 \pm 0.17$ & $0.52 \pm 0.07$ & 29.80 & 1.60 & 37.50 & 4.50 & 0.50 \\
\hline
\end{tabular}

$\mathrm{BD}=$ bulk density, $\mathrm{TD}=$ tapped density, $\mathrm{A} \cdot \mathrm{R}=$ angle of repose, $\mathrm{HQ}=$ Hausner's quotient and $\mathrm{Cl}=$ Carr's compressibility index, $\mathrm{MC}=$ moisture content, $\mathrm{AC}=$ ash content.

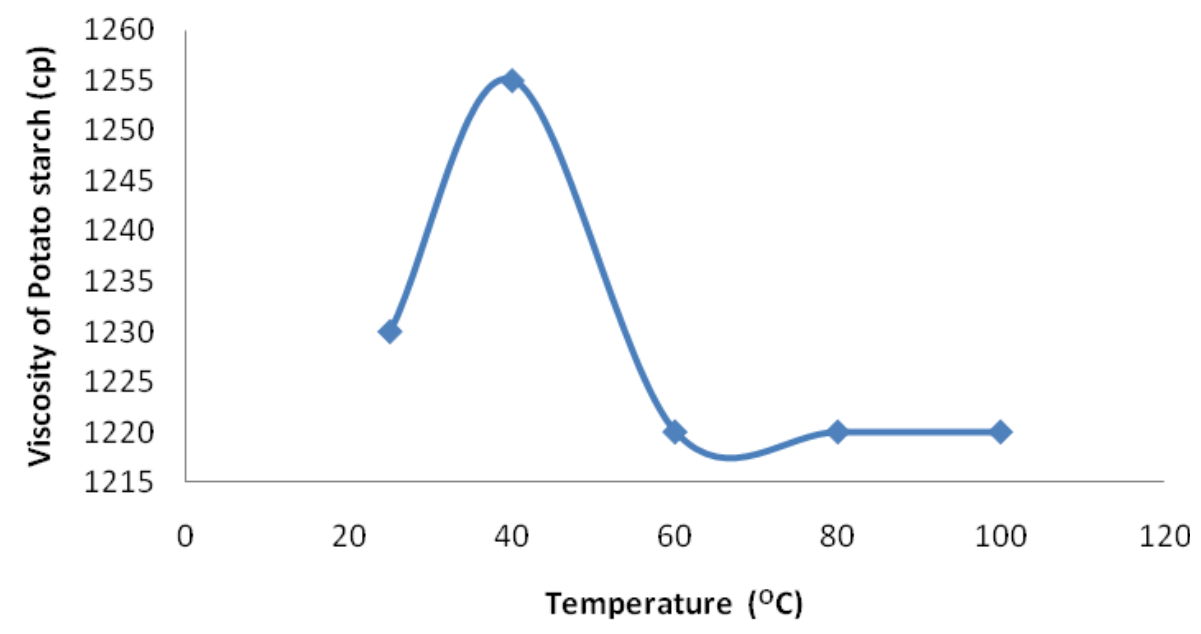

Figure 2. Effect of temperature on the viscosity of potato starch dispersion.

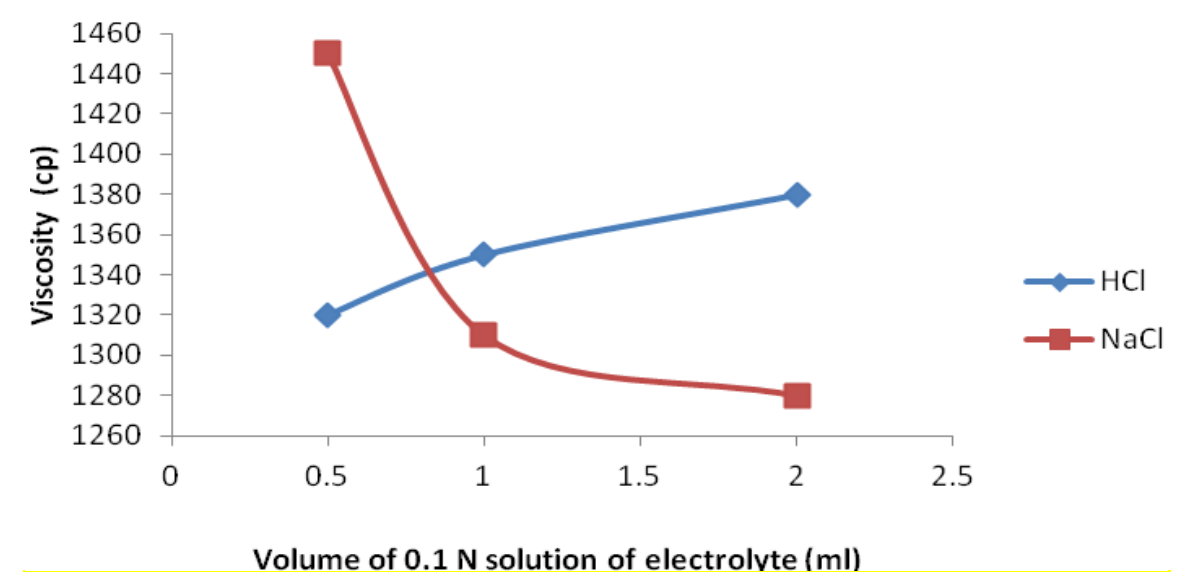

Figure 3. Effect of electrolytes on the viscosity of potato starch dispersions.

powder is low leading to the dispersion thickening quickly as the temperature increased. The rise to a peak temperature leading to high viscosity dropped rapidly on further increase in temperature, indicating little tendency to retrograde as shown in Figure 2. However, the presence and type of electrolytes significantly affected the viscosity of the starch dispersion $(p<0.05)$ as shown in Figure 3; sodium chloride caused a decrease in the viscosity of starch suspension as the concentration increased, while $\mathrm{HCl}$ caused an increase in the viscosity of suspension of starch as the concentration introduced increased.

\section{Rheological properties of acetaminophen suspensions}

Figure 4 shows the rheological properties of acetaminophen suspension formulated with potato starch and two reference suspending agents, acacia and sodium alginate. The results showed that acacia exhibited the highest viscosity of $1,265 \mathrm{cp}$ significantly $(p<0.05)$ different from the tests suspending agent, potato starch. Also, sodium alginate showed higher viscosity value than potato starch. However, increase in concentration of potato starch above $10 \% \mathrm{w} / \mathrm{v}$ did not increase the viscosity 


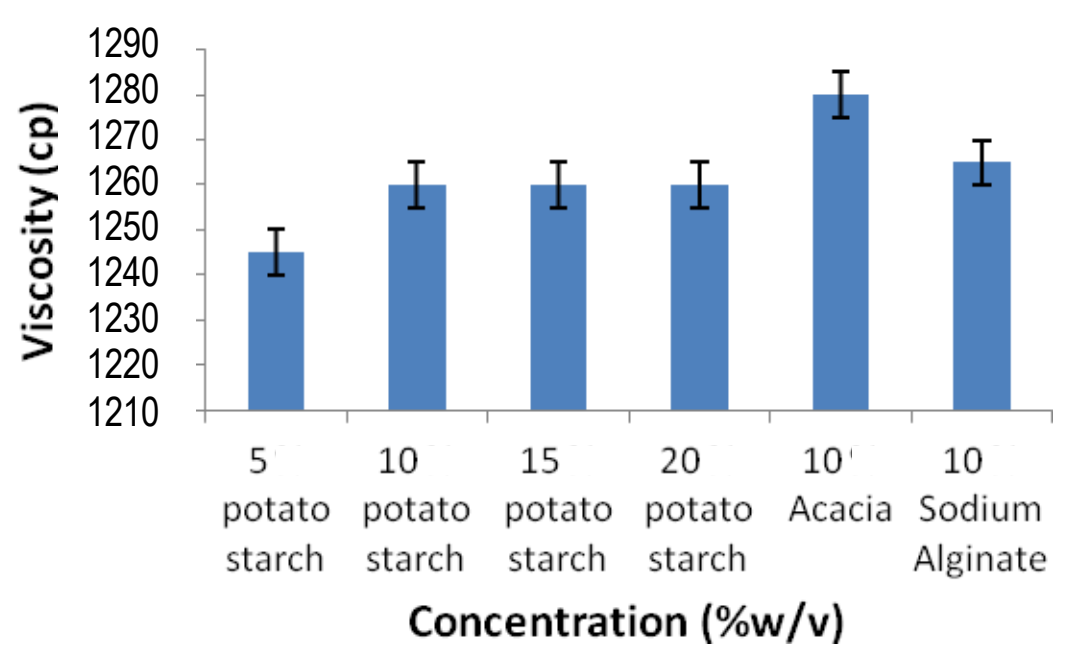

Figure 4. Effect of concentration on the viscosity of acetaminophen suspension formulated with varying concentrations of potato starch compared with sodium alginate and acacia.

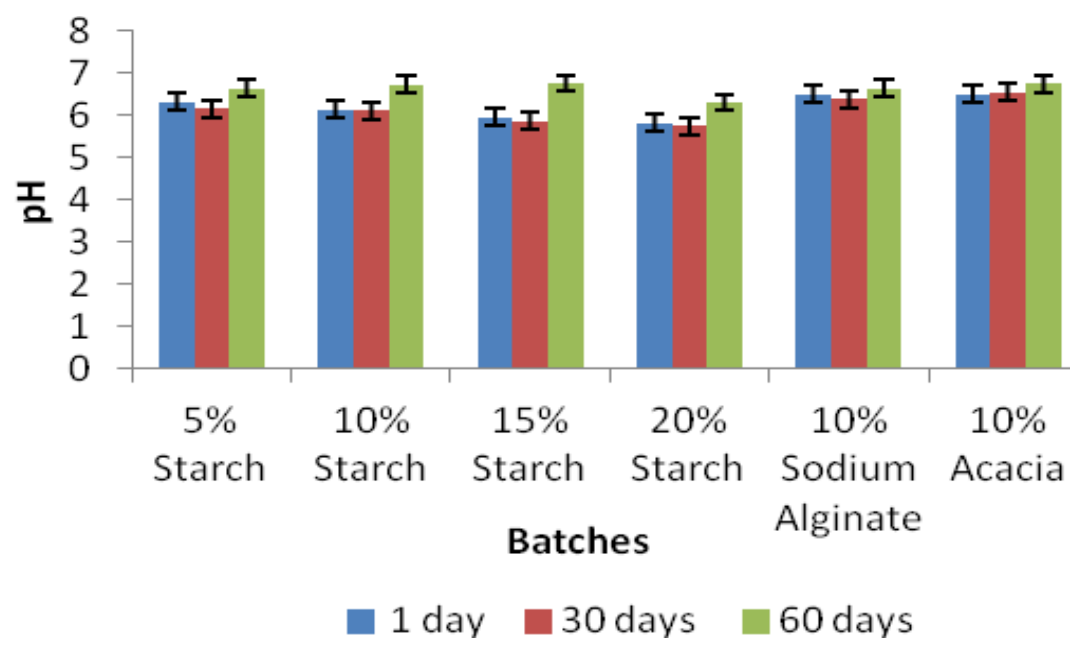

Figure 5. pH stability studies of acetaminophen suspension formulated with potato starch and reference suspending agents, acacia and sodium alginate.

of the suspension of acetaminophen as shown in Figure 4. Therefore, acacia and sodium alginate showed better rheological properties than potato starch in acetaminophen suspensions.

\section{Time dependent pH stability}

The results of $\mathrm{pH}$ stability studies of acetaminophen suspension are shown in Figure 5. From the results, the $\mathrm{pH}$ of all the suspensions slightly increased with time $(p<$ $0.05)$. The results however, showed that the suspensions may require a buffer to keep the $\mathrm{pH}$ more stable. Change in $\mathrm{pH}$ could be a function of degradation of the active pharmaceutical ingredient (API) or excipients. A prior stable API may be affected by degradation of excipients with storage through generation of unfavorable $\mathrm{pH}$ (increase or decrease) or reactive species for the API (Chime et al., 2012; Attama et al., 2009).

\section{Sedimentation volume of suspension}

The results of sedimentation volume of acetaminophen suspension presented in Figure 6 showed that suspension formulated with $20 \% \mathrm{w} / \mathrm{v}$ potato starch was more stable than those formulated with $10 \% \mathrm{w} / \mathrm{v}$ sodium alginate in terms of sedimentation volume. The order of stability of suspension in terms of sedimentation volume could be ranked thus: $E(20 \% \mathrm{w} / \mathrm{v}$ potato starch $)>D$ 


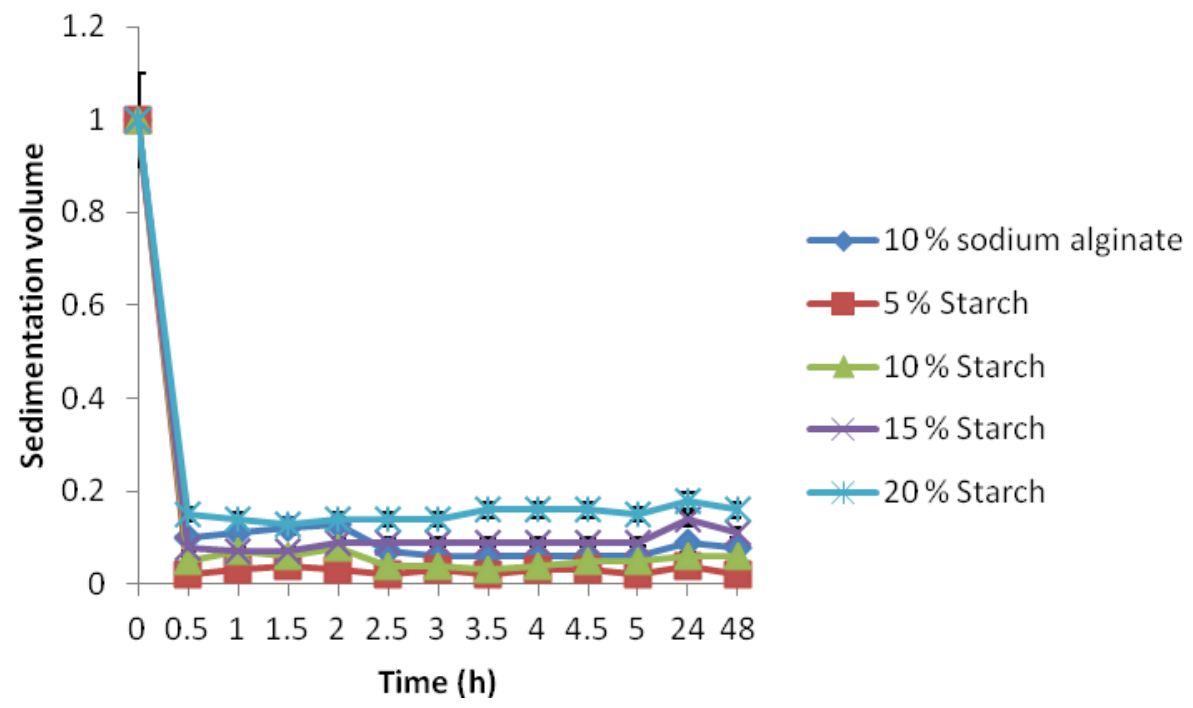

Figure 6. Sedimentation volume of acetaminophen suspension formulated with potato starch and reference suspending agent.

$(15 \% \mathrm{w} / \mathrm{v}$ potato starch $)>\mathrm{F}(10 \% \mathrm{w} / \mathrm{v}$ sodium alginate $)>$ C $(10 \% \mathrm{w} / \mathrm{v}$ potato starch $)>B(5 \% \mathrm{w} / \mathrm{v}$ potato starch $)$.

\section{Conclusion}

Acetaminophen suspensions were successfully formulated using different ratios of potato starch as the suspending agent. The physicochemical properties of potato starch studied showed that it could be used in the formulation of suspensions. The properties of acetaminophen suspensions prepared were comparable to the properties of the reference suspending agents, sodium alginate and acacia used in the study but has advantage over the references which include: the viscosity of potato starch suspension is not affected by temperature fluctuations, it is tasteless, odourless, easy to prepare and relatively cheap.

\section{REFERENCES}

Ajali U (2004). Chemistry of Bio-Compounds. Rhyce Kerex Publishers, Ogui, Enugu, Nigeria: 8-13.

Alebiowu G, Itiola AO (2003). The effects of starches on mechanical properties of paracetamol tablet formulations: Pregelatinization of starch binders. Acta Pharm. 53:231-237.

AOAC, Association of Official Analytical Chemists (1990). Official Methods of Analysis of the Association of Official Analytical Chemists. Washington, D.C.

Attama AA, Okafor CE, Builders PF, Okorie O (2009). Formulation and in vitro evaluation of a PEGylated microscopic lipospheres delivery system for ceftriaxone sodium. J. Drug Deliv. 16:448-616.

Aulton ME (2007). Pharmaceutics; The Science of Dosage Form Design, $3^{\text {rd }}$ Edn. Churchill Living Stone, Edinburgh; 197-210.

Chime SA, Attama AA, Agubata CO, Ogbonna JD, Onunkwo GC (2012). Micromeritic and antinociceptive properties of lyophilized indomethacin-loaded SLMs based on solidified reverse micellar solutions. J. Pharm. Res. 5(6):3410-3416.
Edeoga HO, Okwu DE, Mbaebie BO (2005). Phytochemical Constiuents of some Nigerian medicinal plants. Afr. J. Biotechnol. 4 (7):685-688.

Garr JSM, Bangudu AB (1991). Evaluation of sorghum starch as a tablet excipient, Drug Dev Ind Pharm. 17:1-6.

Harborne JB (1993). Phytochemistry. Academic Press, London, pp. 89131.

Mahmud HS, Oyi AR, Allagh TS and Gwarzo MS (2010). Evaluation of the Suspending Property of Khaya snegalensis Gum in CoTrimoxazole Suspensions. Res. J. Appl. Sci. Eng. Tech. 2(1):50-55.

Malcolm PS (1990). Polymer Chemistry: An Introduction. Oxford University Press, New York; pp. 537-569.

Mbang NF, Musiliu OA and Taiwo OO (2004). Evaluation of the suspending properties of Albizia zygia gum on sulphadimidine suspension. Trop. J. Pharm. Res. 3(1):279-284.

Ngwuluka NC, Idiakhoa BA, Nep El, Ogaji I, Okafor SI (2010). Formulation and evaluation of paracetamol tablets manufactured using the dried fruit of Phoenix dactylifera Linn as an excipient. Res. Pharm. Biotech. 2(3):25-32.

Ogaji JI, Hoag SW (2011). Effect of Grewia gum as a suspending agent on ibuprofen pediatric formulation. AAPS Pharm. Sci. Tech. 12(2):507-513.

Oke OL (1967). The Nutritive Value of Some Nigerian Foodstuff from Animal Origin. West Afr. J. Pharm. 9:52.

Onyechi JO (2008). Introductory formulation Science 2. Global Publishers Nig. Ltd. Nsukka; 25-30.

Reithmeier HJ, Herrmann, Gopferich A (2001). Development and characterisation of lipid microparticles as a drug carrier for somatostatin. Int. J. Pharm. 218:133-143.

Sofowora H (1993). Screening Plants for Bioactive Agents In: Medicinal Plants and Traditional Medicine in Africa, Spectrum Books Ltd., Sunshine House, Ibadan. Nigeria $2^{\text {nd }}$ Edn. pp. 134-156.

Trease GE, Evans WC (2002). Pharmacology. 15thg Edn. Saunders Publishers, London, pp. 42-44, 221-249, 303 -393.

Yüksel N, Türkmen B, Kurdoğlu AH, Başaran B, Erkin J, Baykara T (2007). Lubricant efficiency of magnesium stearate in direct compressible powder mixtures comprising cellactose ${ }^{\circledR} 80$ and pyridoxine hydrochloride. FABAD J. Pharm. Sci. 32:173-183. 